\title{
Computer Application for Simulation of Temperature Distribution Inside the Room
}

\author{
Hana Charvátová ${ }^{1, *}$ and Martin Zálešák ${ }^{2}$ \\ ${ }^{1}$ Tomas Bata University in Zlín, Faculty of Applied Informatics, Regional Research Centre CEBIA-Tech, nám. T. G. Masaryka 5555, \\ 76001 Zlín, Czech Republic \\ ${ }^{2}$ Tomas Bata University in Zlín, Faculty of Applied Informatics, Department of Automation and Control Engineering, nám. T. G. \\ Masaryka 5555, 76001 Zlín, Czech Republic
}

\begin{abstract}
The paper deals with computer testing of the temperature distribution in buildings by using COMSOL Multiphysics software. It is devoted to a description of a computer application created in the Application Builder user interface for simulation of the temperature distribution in a room heated by two heat sources. The application allows you to change geometric dimensions of all elements of the studied model and their spatial distribution, as well as a choice of physical properties needed to access the distribution of temperature in the room depending on the ambient temperature and the heat input of the considered sources. Main functions of the application are presented by simulation of cyclic heating and cooling of the tested room.
\end{abstract}

\section{Introduction}

The constant increase in population living in cities leads to the energy demands of households. Apart from industry and transport, households are currently major energy consumers. In the European Union Member States, the main use of energy by households is for heating their homes (64.7\% of final energy consumption in the residential sector) [1], which causes the ever-increasing global warming of the Earth [2].

Raising living standards in cities while ensuring a negative impact on the environment solves so-called smart cities projects $[3,4]$ which include smart buildings with modern technology to provide the required comfort $[5,6]$. But to reduce the energy demand for buildings heating or cooling, proposals for reconstruction of construction of new buildings should include both stationary parameters of buildings, and also non-stationary boundary and user conditions. To a comprehensive assessment of all major factors, it is necessary to use a combination of experimental testing with modern computer technology that is continuously being developed for engineering and scientific calculations of stationary and non-stationary processes.

In order to use the available computer tools for the simulation of the thermal behavior of systems with accumulation, we are currently testing the COMSOL Multiphysics software. By use COMSOL Multiphysics, we would like to create a complex software tool for the assessment of energy performance of selected models of building parts [7-9]. Our research aims to find a methodology for assessment of the heat-accumulation properties and thermal insulating materials of the external wall. From this aspect,

*e-mail: charvatova@ fai.utb.cz we deal with a study of relationship between the time constant and the constant $\alpha$ [10]. Simultaneously, we would like to ensure the possibility of universal use of this tool not only for specialists who are trained to control the software but also for external users via a web interface. In this regard, we follow the paper [8] in which we presented parameterized room modules enabling users to specify both geometric and physical properties.

In the present paper, we describe a possible method for conversion of these modules into a computer application using the Application Builder interface that is a part of software COMSOL Multiphysics. In the following sections, we describe the physical background of heat transfer in the tested room module, the method used to create an application's user interface, including an example of its main features.

\section{Theoretical description of the studied problem}

For computer simulation by COMSOL Multiphysics software, we use Laminar Flow Interface of the Conjugate Heat Transfer Module. This module is used primarily to model slow-moving flow in environments where temperature and energy transport are also an important part of the system and must be coupled or connected to the fluid-flow in some way. The interface solves the Navier-Stokes equations together with an energy balance assuming heat flux through convection and conduction. The density term is assumed to be affected by temperature and flow is always assumed to be compressible [11]. The basic theoretical relations used by Conjugate Heat Transfer Module for a physical description of our model is described in following subsections $2.1-2.3$. 


\subsection{Heat transfer in solids}

The heat transfer in solids interface is solved in COMSOL for the basic equation (1) [12-14]:

$$
\varrho C_{p}\left(\frac{\partial T}{\partial t}+\boldsymbol{u}_{\text {trans }} \cdot \nabla T\right)+\nabla\left(\boldsymbol{q}+\boldsymbol{q}_{r}\right)=\boldsymbol{Q}_{\text {ted }}+\boldsymbol{Q}
$$

where the symbols denote:

$\varrho$ - density, $\left[\mathrm{kg} \cdot \mathrm{m}^{-3}\right]$;

$C_{p}$ - specific heat capacity at constant stress,

$\left[\mathrm{J} \cdot \mathrm{kg}^{-1} \cdot \mathrm{K}^{-1}\right]$

$T$ - absolute temperature, $[\mathrm{K}]$;

$t$ - time, [s];

$\boldsymbol{u}_{\text {trans }}$ - velocity vector of translational motion, $\left[\mathrm{m} \cdot \mathrm{s}^{-1}\right]$;

$\boldsymbol{q}$ - heat flux by conduction, $\left[\mathrm{W} \cdot \mathrm{m}^{-2}\right]$;

$\boldsymbol{q}_{r}$ - heat flux by radiation, $\left[\mathrm{W} \cdot \mathrm{m}^{-2}\right]$;

$\boldsymbol{Q}$ - additional heat sources, $\left[\mathrm{W} \cdot \mathrm{m}^{-3}\right]$;

$\boldsymbol{Q}_{\text {ted }}$ - thermoelastic damping, $\left[\mathrm{W} \cdot \mathrm{m}^{-3}\right]$.

The conductive heat flux $\boldsymbol{q}$ is given by Fourier's law of heat conduction (2):

$$
\boldsymbol{q}=-k \nabla T
$$

where symbol $k$ means thermal conductivity, $\left[\mathrm{W} \cdot \mathrm{m}^{-1} \cdot \mathrm{K}^{-1}\right]$.

For the steady-state problem, the temperature does not change with time and the terms with time derivatives disappear.

\subsection{Heat transfer in fluids}

The heat transfer in fluids interface is solved for the following basic equation (3) [12]:

$$
\varrho C_{p}\left(\frac{\partial T}{\partial t}+\boldsymbol{u} \cdot \nabla T\right)+\nabla\left(\boldsymbol{q}+\boldsymbol{q}_{r}\right)=\boldsymbol{Q}_{p}+\boldsymbol{Q}_{v d}+\boldsymbol{Q}
$$

where the symbols denote:

$\boldsymbol{u}$ - velocity vector, $\left[\mathrm{m} \cdot \mathrm{s}^{-1}\right]$;

$\boldsymbol{Q}$ - heat sources other than viscous dissipation, $\left[\mathrm{W} \cdot \mathrm{m}^{-3}\right]$.

$\boldsymbol{Q}_{p}$ denotes the work done by pressure changes and is the result of heating under adiabatic compression as well as some thermoacoustic effects:

$$
\boldsymbol{Q}_{p}=\alpha_{p} T\left(\frac{\partial p}{\partial t}+\mathbf{u} \cdot \nabla p\right)
$$

where:

$\alpha_{p}$ - coefficient of thermal expansion, $\left[\mathrm{K}^{-1}\right]$; $p$ - pressure, $[\mathrm{Pa}]$.

\subsection{Convective heat transfer}

The heat transfer between solids and fluids can be described by boundary conditions for convective cooling or heating whereby a fluid cools or heats a surface by natural or forced convection. It is possible to model this process either by using a heat transfer coefficient on the surfaces or by extending the model to describe the flow and heat transfer in the surrounding fluid.

Convective heat flux is solved by the equation (5):

$$
\boldsymbol{n} \cdot \boldsymbol{q}=h \cdot\left(T-T_{\text {ext }}\right)
$$

where:

$\boldsymbol{n}$ - normal vector toward exterior, [-];

$h$ - heat transfer coefficient, $\left[\mathrm{W} \cdot \mathrm{m}^{-2} \cdot \mathrm{K}^{-1}\right]$;

$T_{\text {ext }}$ - external temperature, [K].

Depending on the type of convection conditions and on the type of geometry, it is possible to divide the convective heat flux on natural or forced convection with internal or external flow. In our case, we suppose natural convection with external flow.

For the heat transfer coefficient correlation applied to natural convection on a vertical wall, it holds [12]:

$$
h=\frac{k}{L}\left(0.68+\frac{0.67 \mathrm{Ra}_{L}^{1 / 4}}{\left(1+\left(\frac{0.492 k}{\mu C_{p}}\right)^{9 / 16}\right)^{4 / 9}}\right) \text { for } \mathrm{Ra}_{L} \leq 10^{9},
$$

$$
h=\frac{k}{L}\left(0.825+\frac{0.387 \mathrm{Ra}_{L}^{1 / 6}}{\left(1+\left(\frac{0.492 k}{\mu C_{p}}\right)^{9 / 16}\right)^{8 / 27}}\right)^{2} \text { for } \mathrm{Ra}_{L}>10^{9},
$$

where $\mathrm{Ra}_{L}$ denotes Rayleigh number computed from equation (8):

$$
\mathrm{Ra}_{L}=\frac{g \alpha_{p} \varrho^{2} C_{p}\left|T-T_{\text {ext }}\right| L^{3}}{k \mu} \text { for } 10^{4} \leq \mathrm{Ra}_{L} \leq 10^{13},
$$

$L$ - characteristic length (height of the wall), [m];

$\mu$ - dynamic viscosity, [Pa.s];

$g$ - acceleration of gravity, $\left[\mathrm{m} \cdot \mathrm{s}^{-2}\right]$.

All material properties are evaluated at $\left(T+T_{\text {ext }}\right) / 2$.

For the heat transfer coefficient correlation applied to natural convection on the top surface of on a horizontal wall, it holds [12]:

If $T>T_{\text {ext }}$, then

$$
\begin{aligned}
& h=\frac{k}{L} 0.54 \mathrm{Ra}_{L}^{1 / 4} \text { for } 10^{4} \leq \mathrm{Ra}_{L} \leq 10^{7}, \\
& h=\frac{k}{L} 0.15 \mathrm{Ra}_{L}^{1 / 3} \text { for } 10^{7} \leq \mathrm{Ra}_{L} \leq 10^{11},
\end{aligned}
$$




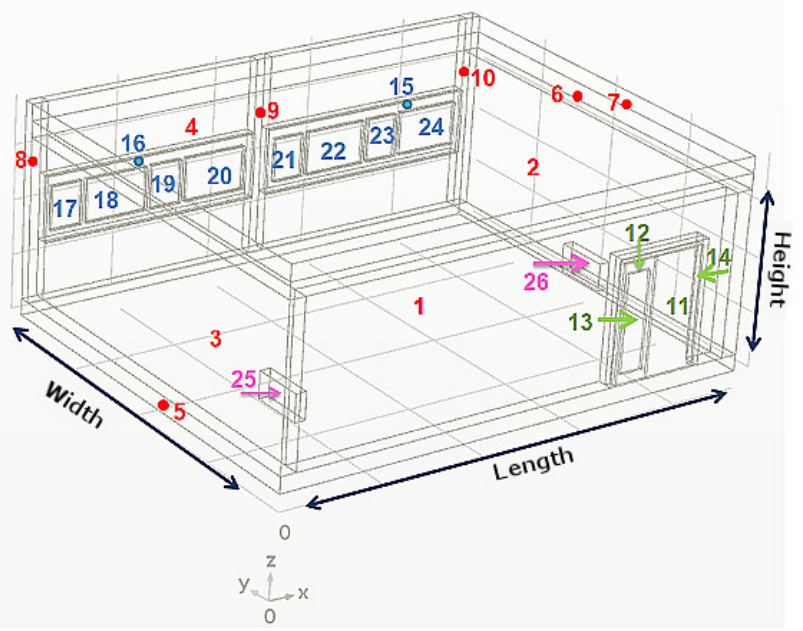

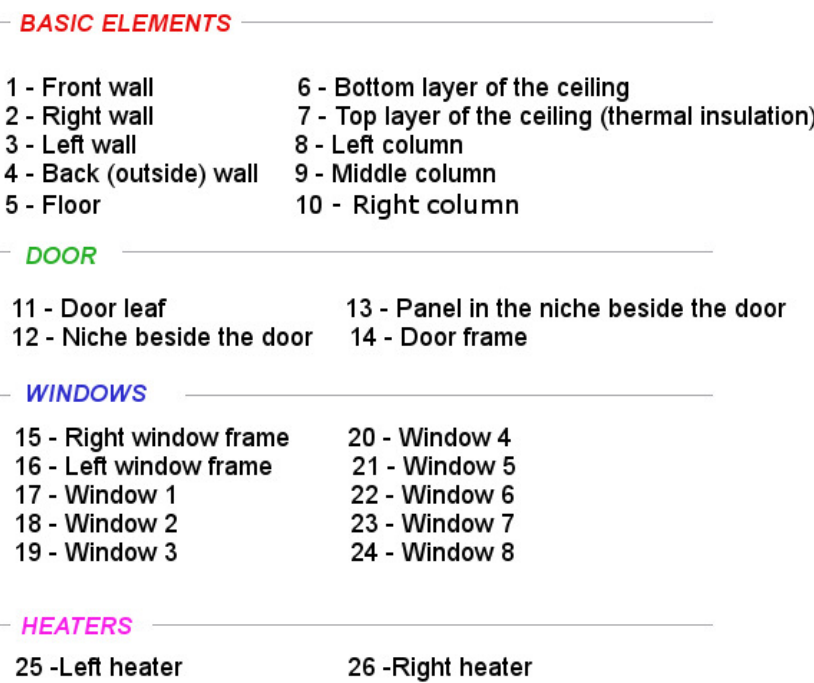

Fig. 1. Geometric sketch of the model.

while $T \leq T_{\text {ext }}$, then

$$
h=\frac{k}{L} 0.27 \mathrm{Ra}_{L}^{1 / 4} \text { for } 10^{5} \leq \mathrm{Ra}_{L} \leq 10^{10} .
$$

$\mathrm{Ra}_{L}$ is given by equation (8), and the characteristic length, $L$, is defined as area.

For the heat transfer coefficient correlation applied to natural convection on the bottom surface of on a horizontal wall, equations (9), (10) hold when $T \leq T_{\text {ext }}$. Equation (11) is used when $T>T_{\text {ext }}[12]$.

\section{Method used for the computer application design}

The basic model for simulation of temperature and heat flow distributions was built in standard Model Builder interface which is designed for users who have knowledge of programming in COMSOL Multiphysics. This parameterized model is described in paper [9]. Its geometry sketch is shown in Figure 1. Solution of the model is based on equations described in previous section 2. To convert the basic model into an application form, we used Application Builder interface that includes many tools which help you to create comfortable computer applications so that the simulations can be performed by a wide range of users, regardless of their knowledge of programming the models in COMSOL Multiphysics. The applications created in the Application Builder can be deployed and used on all operating systems, including running in a web browser together with COMSOL server [12].

\section{Description of the programmed computer application}

As mentioned, the purpose of the application is to study temperature and heat flow distributions in the tested room under the specified winter conditions. Also, the application can be used to estimate the boundary conditions and parameters that can the time evolution influence. The application is designed for a parameterized 3D model with the geometric sketch that is depicted in Figure 1. The basic model contains only elements that significantly affect the heat flow between the rooms and the surroundings. It includes peripheral walls, thermally insulated ceiling and floor. The other geometric elements of the solved model include windows, door and two heaters inside the room. It is also assumed that the ceiling and one wall of the room are in contact with the environment outside of the building.

A user interface of the application is shown in Figure 3. It is structured as a group of user windows arranged in a sequence that corresponds to the process of creating the geometric sketch of the model, defining simulation conditions, calculating and visualising results, including exporting output data. The scheme in Figure 2 demonstrates this process. As is shown, the first step of the model preparation consists of defining the geometric design of the model. The application enables the user to modify dimensions and spatial distribution of all geometric elements of the model. The actual design can be continuously displayed and controlled.

In the second step of the model preparation, physical properties of the model elements can be modified. In our case, the user can modify thermal conductivity, density a and specific heat capacity of all solid materials. Properties

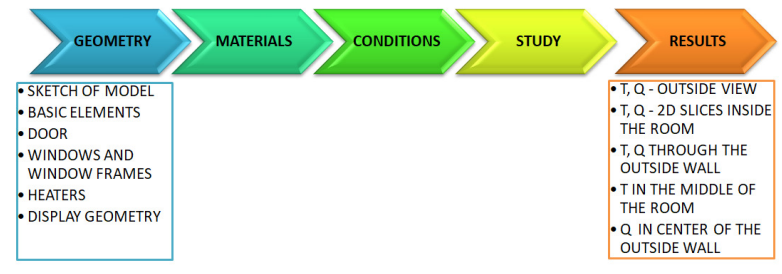

Fig. 2. Sketch of the computer application structure. 


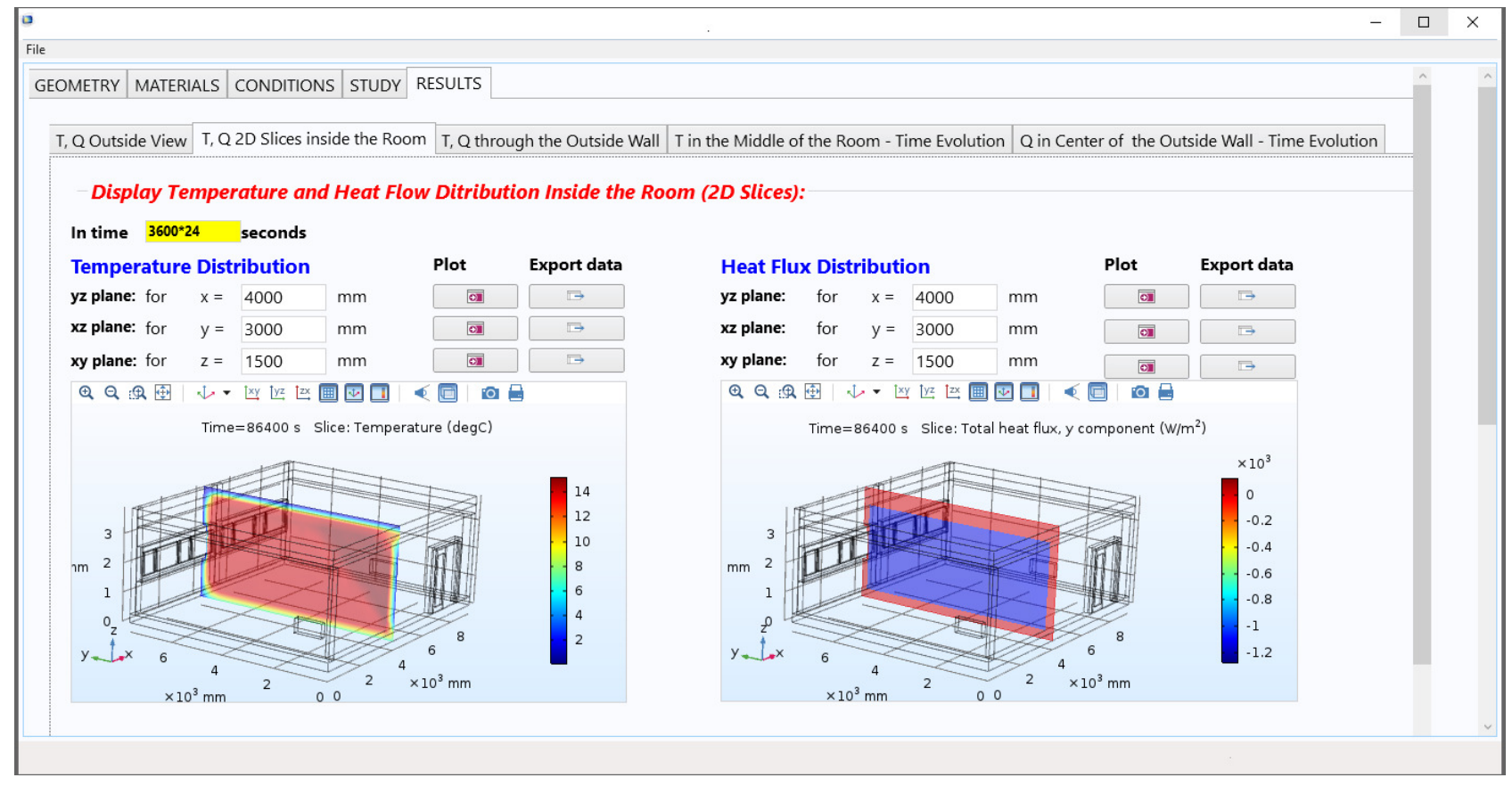

Fig. 3. User interface of the programmed computer application.

of air inside the room are loaded from the Materials library which is a part of the COMSOL Multiphysics tools.

The purpose of the third step is setting initial and boundary conditions necessary for the computer simulation. The user can define the initial temperature of the air inside the room, supposed heat transfer coefficients inside and outside the building. The temperatures of the environment outside the tested room and thermal power of the heaters can be inserted either as constant values to text fields of the application or they can be imported as the time-dependent data. In this case, they need to be defined and changed in the basic version of the model prepared in the Standard Builder of the COMSOL Multiphysics interface.

The fourth step is designed to set numerical calculation parameters and recalculate solutions for modified parameters and model conditions. For this purpose, the user can modify total time and a time step of the simulation. The mesh of the model has to be defined and changed in the basic version of the model prepared in the Standard Builder interface.

In the final step, results of the simulation can be displayed or exported as images or TXT data files. The application allows you to view temperature and heat flow inside the room and in the walls as 2D slices in the selected cuts, the time evolution of the temperature in the middle of the room or time evolution of the heat flow in the center of the outside wall.

\section{Example of the application using}

We demonstrate the above-described method for assessment of temperature distribution in the room which simplified geometric model is shown in Figure 1. It contains only such elements which significantly affect the heat flow between the rooms and the surroundings.

The testing aims to evaluate the influence of the cyclic heating and cooling on the temperature distribution and time evolution of the temperature inside the tested room under the following winter conditions:

- initial air temperature inside the room $21^{\circ} \mathrm{C}$,

- time evolution of the air temperature in the neighbouring rooms is shown in Figure 4a,

- time evolution of power of heaters inside the room is depicted in Figure 4c,

- heat transfer coefficient between the walls of the room and the air inside the building and heat transfer coefficient between the walls of the room and outside air was in COMSOL automatically computed by relations described in section 2.3 ,

- physical properties of all elements of the models are shown in Table 1,

- time evolution of outside air temperature is shown in Figure 4b,

- dimensions of the tested room: length $8.7 \mathrm{~m}$, width $7.2 \mathrm{~m}$, height $3 \mathrm{~m}$,

- thickness of the inner walls, ceiling, and floor $30 \mathrm{~cm}$.

Results of our experiment are presented in Figures 5 8. Figure 5 shows the time evolution of air temperature in the middle of the room during its cyclic heating and cooling. Under given conditions, the temperature increased during the studied time. During the first day of the simulation, when the room was not heated, the inside temperature decreased. After that during cyclic heating by heaters inside the room, the temperature was increased. The total increase during simulation was approximately $0.6{ }^{\circ} \mathrm{C}$. 
Table 1. Properties of the main geometrical elements of the simulated room.

\begin{tabular}{lccc}
\hline $\begin{array}{l}\text { Geometrical } \\
\text { element }\end{array}$ & $\begin{array}{c}\text { Thermal } \\
\text { conductivity } \\
{\left[\mathrm{W} \cdot \mathrm{m}^{-1} \cdot \mathrm{K}^{-1}\right]}\end{array}$ & $\begin{array}{c}\text { Density } \\
{\left[\mathrm{kg} \cdot \mathrm{m}^{-3}\right]}\end{array}$ & $\begin{array}{c}\text { Specific } \\
\text { heat capacity } \\
{\left[\mathrm{J} \cdot \mathrm{kg}^{-1} \cdot \mathrm{K}^{-1}\right]}\end{array}$ \\
\hline Inner walls & 0.27 & 900 & 960 \\
Outside wall & 0.80 & 817 & 900 \\
Floor & 1.43 & 2300 & 1020 \\
Ceiling & 0.82 & 1251 & 1021 \\
Window frame & 0.20 & 420 & 2510 \\
Ceiling insulation & 0.04 & 30 & 1270 \\
Columns in the outside wall & 0.32 & 2192 & 1018 \\
Glass in the windows & 0.76 & 2600 & 840 \\
Window frames & 0.18 & 400 & 2510 \\
Door leaf & 0.11 & 800 & 1150 \\
Niche next to the door & 0.20 & 1380 & 1100 \\
Door frame & 58 & 7850 & 440 \\
Glass door trim & 0.76 & 2600 & 840 \\
Heaters & 58 & 7850 & 440 \\
\hline
\end{tabular}
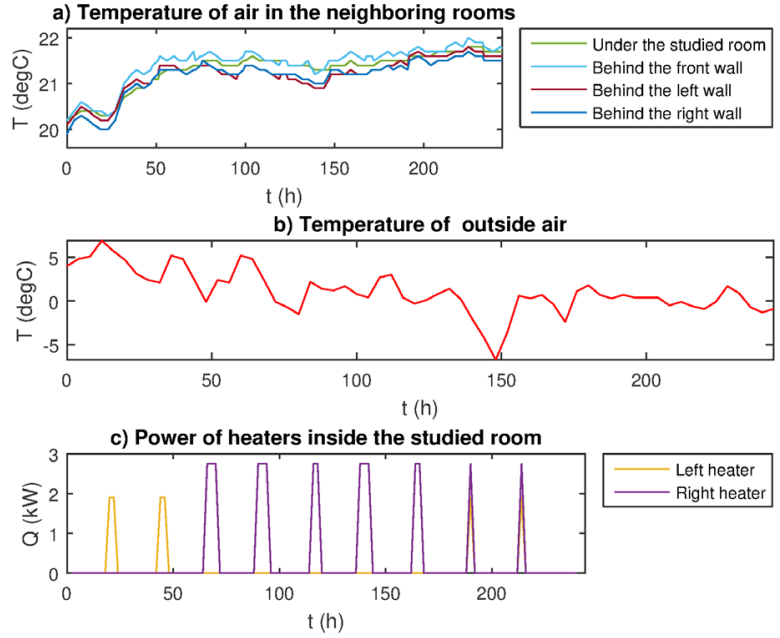

Fig. 4. Boundary conditions used for simulation.

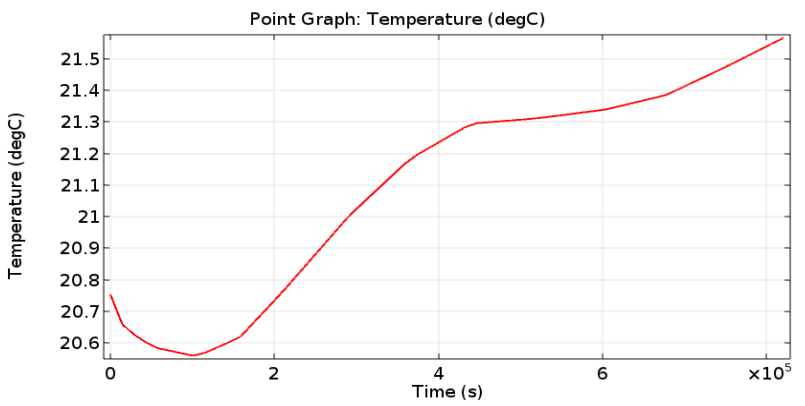

Fig. 5. Time evolution of the air temperature inside the room.

Figure 6 depicts time evolution of heat flux in the middle of the middle of the external wall. The computed heat flux was approximately between $40 \mathrm{~W} \cdot \mathrm{m}^{-2}$ and $64 \mathrm{~W} \cdot \mathrm{m}^{-2}$ except for the initial time of simulation, in which the results were not accurate because the conditions were not included in historical data before the beginning of the simulation.

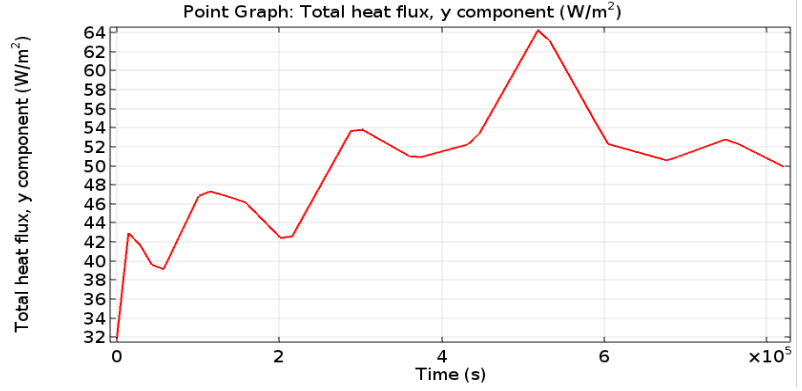

Fig. 6. Time evolution of the heat flux in the outside wall.

Figures 7 - 8 show results of the simulation in the outside wall. Figure 7 demonstrates temperature distribution in center of the wall computed in selected times one day, five days and nine days of heating and cooling the room. Figure 8 shows heat flux for the same conditions. But all computed data can be exported from COMSOL and processed for other studies.

\section{Conclusion}

Application Builder interface enabled transform 3D model designed to test the thermal stability of the room into the computer application which provides the opportunity to use the model for engineers and scientists without the necessary knowledge of COMSOL Multiphysics control.

At present, the programmed application offers testing thermal stability for various geometry size and material properties of all elements of the presented model of a room in conditions corresponding to the winter period.

Further work will be focused on modification of the application for other boundary conditions as well as for other types of construction structures concerning their thermal insulation. We will also deal with the subsequent processing of output data obtained by computer simulations. 


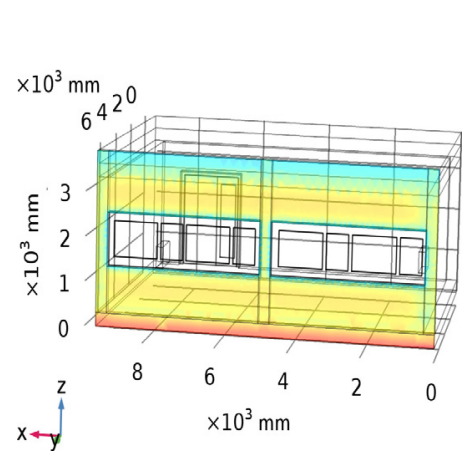

(a) 1 day

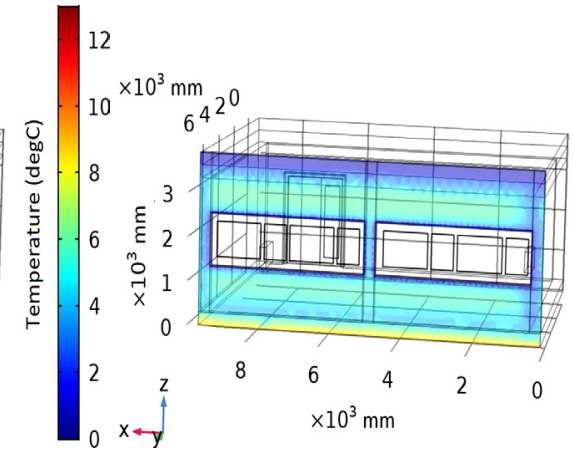

(b) 5 days

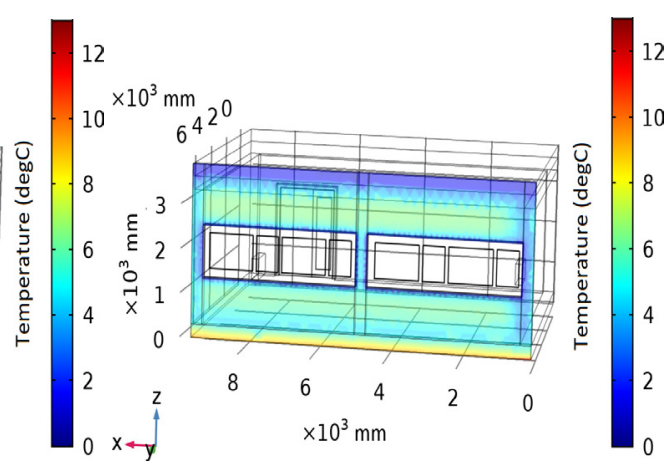

(c) 9 days

Fig. 7. Temperature distribution in the outside wall in selected times of the simulation.

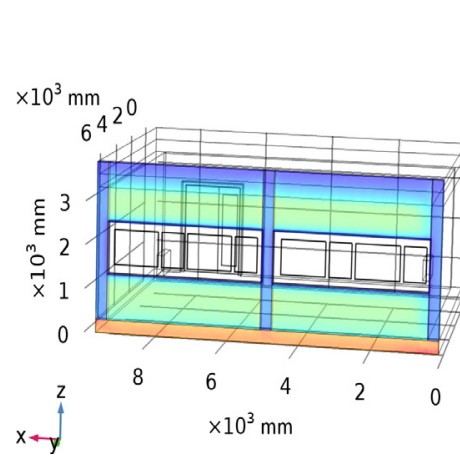

(a) 1 day

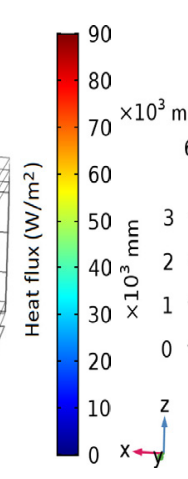

$x+y$

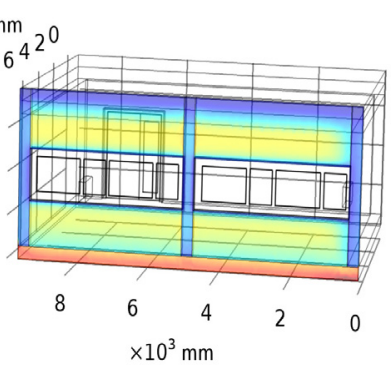

(b) 5 days

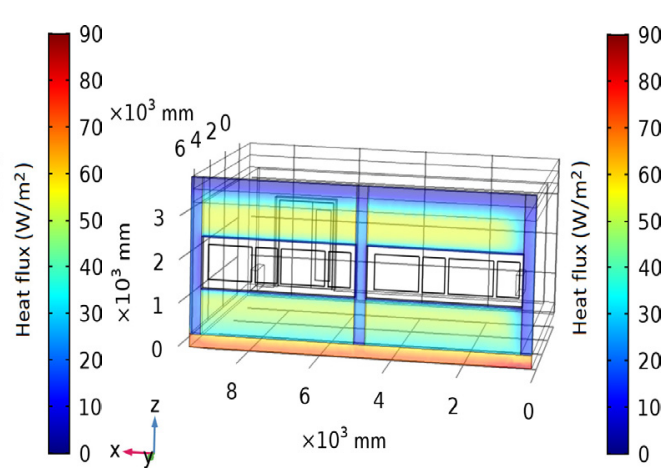

(c) 9 days

Fig. 8. Heat flux distribution in the outside wall in selected times of the simulation.

This work was supported by the Ministry of Education, Youth and Sports of the Czech Republic within the National Sustainability Programme project No. LO1303 (MSMT-7778/2014).

\section{References}

[1] Eurostat. Available online: https://ec.europa.eu/eurostat/ (accessed on 20 April 2018)

[2] European Commission. Climate Action. Available online: https://ec.europa.eu/clima/ (accessed on 20 April 2018)

[3] Z.A. Khan, Sustainable Cities Soc. 40, (2018)

[4] G.C. Lazaroiu, Energy 47, 1, (2012)

[5] M. De Groote, M. Fabbri, Smart buildings in a decarbonised energy system (Buildings Performance Institute Europe (BPIE), Brussels, Belgium, 2016)

[6] T. Weng, Y. Agarval, IEEE Design \& Test of Computers 29, 4, (2012)

[7] V. Gerlich, Verification of Possibility of Using COMSOL Multiphysics as Simulation Tool for Heat Trans- fer Calculation in Systems with Accumulation (Thesis, Tomas Bata University in Zlin, Zlin, 2012)

[8] H. Charvátová, M. Zálešák, S. Sehnálek Proceedings of the 18th International Conference on Systems. Recent Advances in Systems, (Santorini Island, Greece: WSEAS Press, 2014)

[9] H. Charvátová, M. Zálešák Proceedings of the 19th International Conference on Systems. Recent Advances in Systems, (Zakynthos Island, Greece: WSEAS Press, 2015)

[10] H. Charvátová, M. Zálešák WSEAS Transactions on Heat and Mass Transfer 12, (2017)

[11] Heat Transfer Module User's Guide (COMSOL, 2017)

[12] Application Builder Reference Manual (COMSOL, 2017)

[13] G. Nikishkov, Introduction to the Finite Element Method (University of Aizu, 2003)

[14] H. S. Carslaw, J. C. Jaeger, Conduction of Heat in Solids (Clarendon Press, Oxford, 1986) 